\title{
COMMENTARY
}

\section{The Silent Birth: A Feminist Perspective}

\author{
Joanne Cacciatore
}

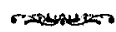

We grieve all that cannot be spoken, that for which there is no name (Griffin, 1978).

$\mathrm{T}$ The social work profession embraces the idea that social action is necessary as a part of the field's responsibility to society. This includes political and social action that seeks to improve the lives of others, particularly the underrepresented and the vulnerable populations (Reamer, 1998). The feminist perspective, a theoretical paradigm often used to examine women's issues and one embraced by many social workers, "rests on the concept of the personal is political" (Collins, 1986, p. 215). There is, perhaps, no more deeply personal and profound experience for many women than losing a baby to stillbirth (Cacciatore \& Bushfield, 2008).

Stillbirth, or sudden intrauterine death, occurs 10 times more frequently than Sudden Infant Death Syndrome, yet it has failed to be acknowledged as a public health problem ("Racial/Ethnic Trends," 2004).This translates to about one in 110 pregnancies that will end in stillbirth. Despite improvements in prenatal care and advanced medical testing, stillbirth rates over the past 10 years have declined only slightly in the United States (Ananth, Liu, Kinzler, \& Kramer, 2005; Goldenberg, Kirby, \& Culhave, 2004; Silver, 2007). Many sudden intrauterine deaths occur at or near full-term to otherwise apparently healthy infants. Upon postmortem examination, one-fourth to one-half of stillborn infants die as a result of causes that are indiscernible (Froen et al., 2001). Mothers, and often fathers, are left searching for answers, for any explanation to the questions surrounding the child's death, often left in the turmoil of irrational self-blame (DeFrain, 1986). Although etiological aspects of stillbirth are cloaked in obscurities, the psychosocial dimensions of grief responses to stillbirth, as well as child death in general, are often even more elusive (Froen et al., 2001; Goldenberg et al., 2004).

The birthing process is often a traumatic physiological event (Silver, 2007; Slade, 2006; Soet, Brack,
\& Dilorio, 2003; Smith Armstrong, 2002; Hendrick, Altshuler, \&: Suri, 1998). Researchers in England discovered that " $20 \%$ of mothers who have a stillbirth experience prolonged depression," and at least one in five suffer from posttraumatic stress disorder (Walling, 2002). Approximately 20 percent to 30 percent of women who have experienced stillbirth exhibit "appreciable psychiatric long term morbidity" (Radestad, Steineck, Nordin, \& Sjogren, 1996). As a result, it is not unusual to observe significant stressors in families after such a tragedy. These disruptions can result in prolonged dysfunction leading to an erosion of familial relationships and, sometimes, even severances. The emotional effects of giving birth and death simultaneously are often misunderstood (Fletcher, 2002; Malacrida, 1997; Michon, Balkou, Hivon, \& $\dot{\mathrm{C} y r}$, 2003) and rarely examined beyond the cursory rhetoric of perinatal death (Cacciatore, 2007). Women who give birth to a dead baby may feel disenfranchised from social groups in which babies and children are integral, while their mourning experience is generally decried by society in general (personal communication with R. E. Kubler, Scottsdale, Arizona, 2004; DeFrain, 1986; Fahey-McCarthy, 2003; Fletcher 2002; Saddler, 1987; Worth, 1997).

Fathers, too, are often faced with tumult after stillbirtl. Both bereaved mothers and fathers demonstrated significantly higher levels of depression from a control group, those effects being longer lasting in mothers up to 30 months after the death (Boyle, Vance, Najman, \& Thearle, 1996; Vance \& Najman, 1995). "Fathers are in a difficult position after a stillbirth for a number of reasons: They are expected to take care of the wife emotionally; they are expected to continue to work and pay the bills; and they need to grieve for their lost baby themselves" (DeFrain, Martens, Stork, \& Stork, 1990, p. 97). Layne (2003) noted that "most men are socialized not to discuss their feelings and to avoid emotionally charged situations"'(p. 1.31). One father said, "I had to be strong...I was told not to show any emotion because it would upset her. It's funny: 
I was hurting too, but I was not expected to show it (Peppers \& Knapp, 1980, p. 53).

\section{POLICY ISSUES RELATED TO SUDDEN INTRAUTERINE DEATH}

Although policies help shape public opinion about the worthiness of a woman's grief experience after a baby is stillborn, they also contribute to misconceptions about the definitions and parameters of sudden intrauterine death and the women who suffer such tremendous loss (Cacciatore, 2007). A country's rate of infant mortality is commonly used as a marker to measure societal well-being. Yet, stillbirths, even at full-term, are not counted in infant mortality data, thus, affecting public perception, funding, and research. Critics assert that this is a public health problem that has been largely overlooked and even ignored. Devaluation and the political status of the unborn (Layne, 2003) and the absence of accurate data have also led to relative inaction by policymakers (Cacciatore \& Bushfield, 2008).

One policy related to stillbirth that has recently come under fire has to do with vital records and data keeping. All 50 states required the issuance of a death certificate and mandated final disposition, through cremation or burial, of stillborn babies.Yet, women wanting a stillbirth certificate for their babies were categorically denied the option to obtain such a document (Cacciatore $\&$ Bushfield, 2008). As one mother described:

I called the vital records office after my baby died. I wanted her birth certificate. They told me I couldn't have one and that I didn't have a real baby. But she was real to me. She was almost ten pounds and the autopsy could not find a cause of death. She was and will always be my child...I've never been so offended. (MISS Foundation, 2005b)

The grassroots efforts of some mothers from an Arizona support group led to the passage of the first law of its kind. Enacted August 9, 2001, House Bill 2416 altered the way in which stillbirths are handled and recorded in the state of Arizona:

ARS 36-329.01 Certificate of Birth Resulting in Stillbirth

A. In addition to the requirements of section 36-329, the state registrar of vital statistics shall establish a certificate of birth resulting in stillbirth on a form approved by the state registrar for each fetal death occurring in this state after a gestational period of at least twenty completed weeks. This certificate shall be offered to the parent or parents of a stillborn child.

Since Arizona's passage of this legislation, 20 other states have passed similar laws, including California. New York is currently considering this legislation, along with seven other states with pending bills. Supporters contend that there are tangible psychological and geneological benefits to the issuance of the new certificate recognizing the birth (Lewin, 2007). Throughout childhood and adolescence, individuals acquire material items in day-to-day life; objects that abet memories, and those memories are attached to family narrations. Yet, there are few tangible mementos for mothers and fathers whose babies are stillborn. These "emotional artifacts," (Layne, 2003) such as a birth certificate, help women actualize their losses and may help them to cope with their losses.And women whose babies die as a result of stillbirth must still give birth. This recognition is crucial to many women and has captured the attention of the mainstream media, including the New York Times, Boston Globe, Stateline, and CNN (Gardner, 2007; Lewin, 2007; "Richardson Must Apologize," 2007; Vestal, 2007). Yet, this piece of legitimacy for grieving mothers has faced substantial opposition in some states, including California where it was finally signed into law in October 2007 and in New Mexico where it was vetoed (Lewin, 2007; "Richardson Must Apologize," 2007).

Other significant legislative changes have also occurred since the late 1990s. For example, in Arizona in 2002 the MISS Foundation successfully passed SB2001, the inception of the Unexplained Infant Death Advisory Council, an interdisciplinary committee charged with investigating data on infant deaths, from stillbirth to age three, for which there is no obvious cause. Under Arizona Revised Statutes section 36-2291, although the ultimate goal of a death scene investigation is to accurately assign a cause of death, equally important goals are the identification of health threats posed by consumer products; identification of risk factors associated with unexplained infant deaths; and the referring of families to grief counseling and support groups (Arizona Department of Health Services, 2007).The committee would be charged with collecting data 
and issuing reports to the governor in an effort to reduce the number of stillbirths and unexplained child deaths in Arizona. Also, in May 2004 Arizona Governor Janet Napolitano signed SB1003 into law, an act that allows for a one-time tax deduction of $\$ 2,300$ for families experiencing stillbirth during the same year in which the birth and death occurred (MISS Foundation, 2005a).This is intended to offset the costs associated with the birth (hospital expenses, childbirth preparation, ultrasounds, and other testing) and the death (final disposition expenses).

The National Institutes of Health (NIH) acknowledges that little is known about the etiology of stillbirth (Alexander, 2003). Federally funded research has followed the trend: For the first time, the NIH, during 2003, earmarked funding for the creation of the Stillbirth Research Collaborative Network (SRCN)-five university-based research centers around the country and an independent data center-to collect and analyze statistics on stillbirth (NIH, 2003).The research centers are collaborating with NIH to determine the causes of stillbirth. The five-year effort also seeks to develop standardized research guidelines for reporting and investigating stillbirths. The five universities involved in the SRCN are Brown University, Emory University, University of Utah, University of Texas Medical Branch, and University of Texas at San Antonio, plus a data coordinating center at Research Triangle. These research centers are currently working with local hospitals to identify and track stillbirths. The three specific aims of this five-year study are to

1. obtain a geographic population-based determination of the incidence of stillbirth, defined as fetal death at 20 weeks gestation or greater

2. determine the causes of stillbirth using a standard stillbirth postmortem protocol that includes a review of clinical history, protocols for autopsies and pathologic examinations of the fetus and placenta, and other postmortem tests to illuminate genetic, maternal, and other environmental influences

3. elucidate risk factors for stillbirth (National Institute of Child Health and Human Development, 2007).

Interdisciplinary teams including obstetricians, nurses, social workers, and grief counselors participating in the research initiative are also charged with providing bereavement support for the mothers and their families.

\section{SOCIAL WORK'S ROLE}

Social work requires an integrative worldview. According to Bartlett (1970), this type of thinking supports emotional and rational aspects of issues and "requires a balance between our accountability and our concern with things that cannot be quantified" (Collins, 19836, p. 218). Although it may seem that stillbirth is an emotion-based, social problem, there are rational imperatives for social work's response. Indeed, there is an obligation for a larger shift in the macro culture; a shift that will likely sway attitudes, beliefs, and values about women experiencing stillbirth. In particular, feminist-minded social workers should be concerned with this uniquely woman's issue. The shift needs to begin with subtle changes to deconstruct the way that stillbirth is perceived and to allow women who have undergone stillbirth to construct their own realities about their losses. Social workers, particularly in hospitals or as clinicians, have an opportunity to become involved in helping women find their voices after the death of a baby. This position is congruent with social work values such as advocacy and social change, selfdetermination, and service. By adding stillbirth issues to their agenda, social workers can break the silence around stillbirth, acknowledging these women as mothers and providing dignity and recognition for their loved-and-longed-for babies (Cacciatore $\&$ Bushfield, 2008). The landscape of stillbirth is rapidly changing. Women, and even men, are no longer finding themselves navigating "an unanticipated journey with outdated maps that no longer accurately represent the sociocultural geography" of their grief (Layne, 2003, p. 236). Improved standards of compassionate care in hospitals, supportive nurturance from family and friends, and support groups contribute to a lessening of posttraumatic stress responses and chronic, debilitating grief (Cacciatore, 2007). These types of systemic changes and grassroots efforts are giving women words-the language - to speak about their losses, and when individuals can find words to capture an experience, society's responses to those experiences slowly evolve in understanding. Legitimization for these grieving mothers and fathers, through policy changes as well as education, research, and advocacy, is a long overdue change. And it is a change that can be supported by academics, clinicians, and policymakers interested in 
social justice. The time has come for these mothers to find their "power over mourning language" and use their voices to influence relevant policies, even when their pain is "pathologized, marginalized, and otherwise restricted" (Kanter, 2002). It is an opportunity for feminist social workers to respond thoughtfully to a historically marginalized group of grieving parents. And the hope is that as this social movement gains momentum, women experiencing stillbirth will no longer have to mourn their losses in the same silence in which their dead children were born. $\mathbf{S W}$

\section{REFERENCES}

Alexander, D. (2003). National institute funds major efforts to determine extent and causes of stillbirth. Retrieved June 18, 2007, from http://www.nichd.nih.gov/news/ releases/stillbirth.cfm

Ananth, C.V., Liu, S., Kinzler, W. L., \& Kramer, M. S. (2005). Stillbirths in the United States, 1981-2000: An age, period, and cohort analysis. American Journal of Public Health, 95, 2213-2217.

Arizona Department of Health Services. (2007). What is the unexplained infant death council? Retrieved June 17 , 2007, from http://www.azdha.gov/phs/owch/uid.htm

Bartlett, H. (1970). The common base of social tvork practices. Washington, DC: National Association of Social Workers.

Boyle, F. M.,Vance, J. C., Najman, J. M., \& Thearle, M. J. (1996). The mental health impact of stillbirth, neonatal death or SIDS: Prevalence and patterns of distress among mothers. Social Science \& Medicine, 43, 1273-1282.

Cacciatore, J. (2007). Effects of support groups on post traumatic stress responses in women experiencing stillbirth. Omega, 55(1), 71-91.

Cacciatore, J., \& Bushfield, S. (2008). Stillbirth: A sociopolitical issue. Affilia, 23, 378-387.

Collins, B. (1986). Defining feminist social work. Social Work, 31, 214-219.

DeFrain, J. (1986). Stillborn: The invisible death. Lexington, MA: Rowman \& Littlefield.

DeFrain, J., Martens, L., Stork, J., \& Stork, W. (1990). The psychological effects of a stillbirth on surviving family members. Omega, 22(2), 81-108.

Fahey-McCarthy, E. (2003). Exploring theories of grief: Personal reflection. British Journal of Midwifery, 11, 595-600.

Fletcher, P. N. (2002). Experiences in family bereavement. Family and Community Health, 25(1), 57-71.

Froen, J. F., Arnestad, M., Frey, K., Vege, A., Saugstad, O, \& Stray-Pederson, B. (2001). Risk factors for sudden intrauterine unexplained death: Epidemiologic characteristics of singleton cases in Oslo, Norway from 1986 to 1995. American Journal of Obstetrics and Gynecology, 184, 694-702.

Gardner, M. (2007, June 4). Legislation on stillbirths entangled in abortion fight. San Diego Tribune. Retrieved June 6,2007, from www.signonsandiego.com

Goldenberg, R. L., Kirby, R., \& Culhave, J. F. (2004). Stillbirth: A review. Journal of Maternal-Fetal and Neonatal Medicine, 16, 79-95.

Griffin, S. (1978). Woman and nature. New York: Harper \& Row.

Hendrick, V., Altshuler, L. L., \& Suri, R. (1998). Hormonal changes in the postpartum and impli- cations for postpartum depression. Psychosomatics, 39(2), 93-101.

Kanter, J. (2002). Hopeful sentences: Gender and mourning language in two contemporary narratives. Women and Language, 25(1), 1-8.

Layne, L. L. (2003). Motherhood lost: A feminist account of pregnancy loss in America. London: Routledge.

Lewin, T. (2007, May 22). A move for legal certificates of stillborn births. New York Times. Retrieved May 22, 2007, from http://www.nytimes.com/2007/05/22/ us $/ 22$ stillbirth.html?ex $=1337486400 \&$ en $=$ $73 \mathrm{c} 976 \mathrm{c} 3 \mathrm{f} 57 \mathrm{~d} 2 \mathrm{e} 6 \mathrm{a} \& \mathrm{ei}=5124 \&$ partner $=$ newsvine $\&$ exprod=newsvine

Malacrida, C. A. (1997). Perinatal death: Helping parents find their way. Joumal of Family Nursing, 3, 130-148.

Michon, B., Balkou, S., Hivon, R., \& Cyr, C. (2003). Death of a child: Parental perception of grief intensity. End of Life and Bereavement Care, 8(6), 363-366.

MISS Foundation. (2005a). Legislative reference page. Retrieved June 8,2007, from http://www. missingangelsbill.org

MISS Foundation. (2005b). Position statement on Pregnancy Loss Awareness Movement. Retrieved June 8, 2007, from www.missfoundation.org/advocacy

National Institute of Child Health and Human Development. (2007). Stillbirth collaborative research network. Retrieved May 23, 2007, from http://www. nichd.nih.gov/research/supported/scrn.cfm

National Institutes of Health. (2003). NICHD funds major effort to determine extent and causes of stillbith. Retrieved May 23, 2007, from http://www.nih.gov/ news/pr/nov2003/nichd-19.htm

Peppers, L. G., \& Knapp, R. J. (1980). Motherhood and mourning. New York: Praeger.

Racial/Ethnic Trends in Fetal Mortality, United States, 1999-2000. (2004). Morbidity and Mortality Weckly Report, 53(24), 529-532.

Radestad, I., Steineck, G., Nordin, C., \& Sjogren, B (1996). Psychological complications after stillbirthInfluence of memories and immediate management: Population based study. British Medical Journal, 312, $1505-1508$.

Reamer, F. G. (1998). Ethical standards in social work: $A$ revicw of the NASW code of ethics. Washington, DC: NASW Press.

Richardson must apologize for insensitivity to parents (2007,April 17). The Daily Lobo. Retrieved April 17, 2007, from http://www.dailylobo.com/media/ storage/paper344/news/2007/04/17/Opinion/ Richa rdson.Must.Apologize. For.Insensitivity. To.Parents-2846341.shtml

Sadler, M. E. (1987). When your patient's baby dies before birth. RN, 50, 28-31.

Silver, R. (2007). Fetal death. Obstetrics and Gynecology, 109(1), 153-165.

Slade, P. (2006). Towards a conceptual framework for understanding posttraumatic stress symptoms following childbirth and implications for further research. Journal of Psychosomatic Obstetrics \& Gynecology, 27(2), 99-105.

Smith Armstrong, D. (2002). Emotional distress and prenatal attachment in pregnancy after perinatal loss. Journal of Nursing Scholarship, 34, 339-345.

Soet, J. E., Brack, G. A., \& Dilorio, C. (2003). Prevalence and predictors of women's experience of psychological trauna during childbirth. Birth, 30(1), 36-46.

Vance, J. C., \& Najman, J. M. (1995). Psychological changes in parents eight months after the loss of an infant from stillbirth. Pediatrics, 96, 933-938.

Vestal, C. (2007). Stillborn laws entangled in abortion debate. Stateline. Retrieved June 8, 2007, 
from http://www.stateline.org/live/details/ story?contentId $=208701$

Walling, A. (2002). Should mothers see their infants after stillbirth? American Family Physician, 66, 1956-1968. Worth, N. J. (1997). Becoming a father to a stillborn child. Clinical Nursing Rescarch, 6, 71-89.

Joanne Cacciatore, $\mathrm{PhD}, \mathrm{MSW}$, is assistant professor, $D e$ partment of Social Work, Arizona State University, P.O. Box 37100,Phoenix,AZ 85069-7100; e-mail:Joanne.cacciatore@ asu.edu.

Original manuscript received April 18, 2008

Final revision received June 19, 2008

Accepted July 11, 2008

\section{Do Something POWERFUL}

\section{JOIN A SPECIALTY PRACTICE SECTION!}

NASW Specialty Practice Sections (SPS) link you to the key information, resources, and expertise you need to stay at the forefront of your practice specialty. Each Section offers members the opportunity to earn

FREE continuing education credits.*

\section{- NEW BOOKS •} (Borrow or Buy)

NEW CE COURSES:

Metacognitive Therapy for Anxiety and Depression (10 credits)

\section{Children with Sexual Behavior}

Problems (9 credits)

\section{Pathways to Change: Brief Therapy} with Difficult Adolescents $\left(2^{\text {nd }}\right.$ ed. $)(10$ credits)

Preventing Boundary Violations in Clinical Practice (10 credits)

\section{Attachment-Focused Family Therapy} (9 credits)

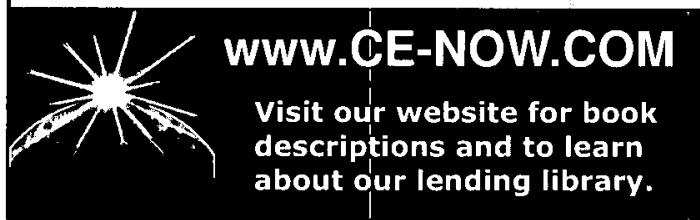

\section{SPECIALTY PRACTICE SECTIONS}

Aging

- Alcohol Tóbacco \& Other 3 Drugs (AT⿱ODODO)

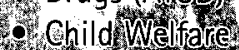

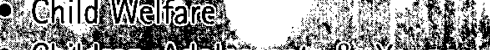

- conilden Adolescents \& Young

7.

* *

Heallthe

Mental

- Private Practice

- School Social Work

- Social and Economic Justice \& Peace

"You must be a current NASW member to join a Specialty Practice Section.

\section{JOIN TODAY!}

www.socialworkers.org/sections

202.408.8600 ext. 476

(1) NASW.SPS

Nutional Association of Social Workers Specially Practice Sections 
Copyright of Social Work is the property of National Association of Social Workers and its content may not be copied or emailed to multiple sites or posted to a listserv without the copyright holder's express written permission. However, users may print, download, or email articles for individual use. 